\section{On 60 and Coffee Rooms}

This year, the 60th anniversary of D-Day (June 6, 1944) was celebrated in Europe and the United States. The special nature of this anniversary is that very few of those who lived through D-Day will be around for the 70th or 75th celebrations, and this causes many of us to pause and consider not only our own mortality but also the special nature of the period of 60 years. This is the length of time which many men, and more women, in the Western world can expect to spend as an adult. It is the period after graduation during which those who chose to be scientists or engineers can expect to continue to learn, understand, and be intrigued by new discoveries and inventions.

Having recently turned 60 (only physically, of course, not mentally), I started to muse on 60-hood. I have not yet lived 60 years as a scientifically trained adult, but one of the most incredible things about living through 50 years of technological progress (as I was not properly aware until I reached the age of 10) is the realization of just how much has happened in that time and just how much has not.

Starting with the 1960s themselves, some 60-things have scarcely changed since those days. We still have a $60 \mathrm{mph}$ speed limit on most roads in the United Kingdom and in some U.S. states, there are still 60 seconds in a minute and 60 minutes in an hour (but not 60 minutes of programming in an hour of TV), we still have 60-watt light bulbs (although 12-watt low-energy versions are rapidly takwith atomic number 60 is still neodymium. $60 \%$ is what you do not have to know to pass an exam at $40 \%$. $60 / 40$ brass (copper/zinc) and 60/40 solder (tin/lead) are still in widespread use, and flipchip technology has created a resurgence of interest in solders.

So what is new? The 60 GB hard drive this Word file is stored on; $60 \mathrm{MB}$ of USB storage for $\$ 60 ; \mathrm{C}_{60}$ and all its derivatives; Nd-Fe-B supermagnets containing element 60; and the principal EELS edges for lithium and selenium are at (almost) $60 \mathrm{eV}$-okay, they always have been, but in the '60s, nobody knew or cared!

Leaving 60 aside for a moment, just reflect on nanotubes, light-emitting polymers, STM, AFM, fractals, the word "photonic," MOSFETs, quantum dots, GaN, cubic BN, DLC, Kevlar, self-assembly, thermochromics, HTC, inkjet technology, and metallic glasses. All of these topics were not known (nor, in most cases, even thought of) when I graduated. I have subsequently worked on about three of them.

How did I learn about the others? The politically correct answer might be to say that as a chartered professional engineer, I am fully committed to continuing proing their place), and the element fessional development (CPD, also called "lifelong learning," or LLL), and I have been attending updating courses for a week or more of each year of my working life. This would of course be untrue for me-and, I suspect, for most of us. However, I do believe that I have picked up enough to understand the context and key issues around each new topic.

How was this done? Surfing from room to room at MRS Meetings; regularly reading one or more professional journals like MRS Bulletin, Materials World, Materials Today, and Physics World; and spending time as often as I can in departmental coffee roomsours at Liverpool when I am at home, and yours in your lab when I am visiting.

The coffee room is actually the most useful resource of all because it occurs almost daily; it is unthreatening and noncompetitive; and at 60, I can ask any question I like, however stupid it might turn out to be. Long live coffee rooms! By the way, did you know that bulk coffee comes in $60 \mathrm{~kg}$ bags?

Peter GoOdHew 